Research Article

\title{
Delivering Sustainable Solutions through Improved Mix and Structural Design Functions for Bitumen Stabilised Materials
}

\author{
K. J. Jenkins $\mathbb{D}$, C. E. Rudman, and C. R. Bierman \\ Stellenbosch University, Stellenbosch, South Africa \\ Correspondence should be addressed to K. J. Jenkins; kjenkins@sun.ac.za
}

Received 5 November 2019; Accepted 24 December 2019; Published 12 March 2020

Guest Editor: Alan Carter

Copyright (C) $2020 \mathrm{~K}$. J. Jenkins et al. This is an open access article distributed under the Creative Commons Attribution License, which permits unrestricted use, distribution, and reproduction in any medium, provided the original work is properly cited.

\begin{abstract}
The evolution of cold recycling using bitumen stabilisation technology has been supported by progressive research initiatives and best practice guidelines. The first generic guidelines for bitumen stabilised materials (BSMs) were published only in 2002. These guidelines provided a generic approach for the analysis of foamed bitumen and bitumen emulsion technologies. From that point, bitumen stabilisation became the common term for the inclusion of either of the two bituminous binders. The TG2 $2^{\text {nd }}$ edition guideline of 2009 took a bold step recognising the shear properties of the bitumen stabilised material (BSM) as the key performance indicators. In addition, advancements in structural design and application of BSMs provided practitioners with robust guidelines. The subsequent decade has provided an opportunity to interrogate data from more than 300 BSM mix designs and 69 LTPP sections. The data have led to research developments including significant new performance properties of BSMs, refined mix design methods, and updated new pavement design methods. This includes an entire design process that has been updated with a streamlined mix design procedure and a new frontier curve for the pavement number design method, as well as a new mechanistic design function. It is anticipated that the research findings and implementation of the newly developed technology will lead to improved application in BSM technology.
\end{abstract}

\section{Introduction}

Since the 1950's, there has been a strong emphasis on finding efficient, cost-effective pavement rehabilitation technologies. Part of this history included Prof. Csanyi [1] experimenting with hot bitumen and water in order to expand its volume and thus improve dispersion in marginal materials at ambient temperatures. Csanyi's development of foamed bitumen using steam was taken further by Acott and Myburgh [2] and Ackeroyd and Hicks [3, 4]. At that time, the impact that foamed bitumen technology was about to have on pavement rehabilitation and sustainable practice was not yet apparent.

In the 1990's, the patent rights that Mobil bought from Csanyi lapsed. In the interim, Mobil developed the foaming technology further by applying accurate dosages of water rather than steam. Applications of foamed bitumen to stabilise crushed aggregates, gravels, sands, and recycled asphalt provided good performance. At the same time, bitumen emulsion provided an alternate way to stabilise base layers. Both foam and emulsion technologies were providing flexible and durable bases for a range of rehabilitated pavement structures using cold recycling. The need for rigorous mix design methods and structural design procedures led South Africa to develop guidelines and manuals for granular emulsion mixes (GEMS) [5], emulsion-treated bases (ETBs) [6], and foamed bitumen-treated materials [7]. A generic term for the two bitumen binders was created under the title of bitumen stabilised materials (BSMs). The structural design of BSM began with the Sabita GEMS and ETB Manuals, which incorporated mechanistic-empirical (ME) design functions.

In 2002, the first Technical Guideline TG2 was published, for foamed bitumen materials. In TG2, a mechanistic-empirical (ME) structural design function was provided for pavements including cold recycling. However, this function was based on only one data set and was found to be conservative. In 2009, the second edition of TG2 was 
released and included a new design method, the pavement number, and the associated design equivalent material slassification System. There was no inclusion of $\mathrm{ME}$ function.

Ever increasing economic and environmental pressures drive the development of more effective technologies for road construction and rehabilitation. By 2009, overwhelming evidence of the primary distress mechanism for BSMs being permanent deformation and not fatigue cracking was identified. Although the principle of BSM being a noncontinuously bound material is well understood, the prediction of long-term stiffness behaviour and permanent strain development has not been developed to the same degree [8].

Long-term pavement performance (LTPP) sections, i.e., 20 field sites and 7 accelerated pavement testing (APT) sites with 22 sections tested by the Heavy Vehicle Simulator (HVS) tester formed the basis of the data for the 2009 guidelines.

Following this trend, the additional performance data related to pavements with both BSM-foam and BSMemulsion were expanded in the 10 years following 2009. This paper addresses the developments in mix design and pavement design of BSM based on updated performance data from the LTPP and APT sections. In addition, a new mechanistic-empirical design function has been developed in this period.

The noncontinuous binding behaviour of BSMs is explained in the Asphalt Academy's Technical Guideline (TG2) [9]. The failure mechanism of BSMs, permanent deformation, is also thoroughly explained in the TG2. The design of BSMs should focus on permanent deformation in the layer. The current design methods, specifically the pavement number (PN) method, are based on experience and tend to be very conservative. This paper aims to present a design function for BSMs which relates mechanical material properties and stress conditions to pavement life based on field observations.

\section{Background}

2.1. Defining a BSM. Firstly, it is important to provide a brief description of BSM technology and what sets it apart from grave emulsion and cold patching mixes. Bitumen stabilisation is typically used in the rehabilitation of existing pavement base layers (granular, cemented, or asphalt) using either foamed bitumen or bitumen emulsion. The granular material is treated with small amounts of bitumen, i.e., less than $3 \%$. A small amount of active filler, typically $1 \%$, is used in the mix to improve the bitumen adhesion to the aggregate. The resulting material is a noncontinuously bound material that differs from hot mix asphalt (HMA) and cement-stabilised material. Stabilisation with bitumen significantly increases the cohesion of the aggregate particles with little or no change in the angle of friction.

The role of the BSM base in a pavement structure is to protect the underlying layers and subgrade from excessive stresses imposed by traffic. BSMs, with resilient modulus values of typically 600 to $1400 \mathrm{MPa}$, effectively achieve distribution the imposed loads. In this way, the BSM layer provides intermediate stiffness values between the high modulus of the asphalt layers above and granular support below, thus creating a balanced system to achieve the desired design structural capacity.

2.2. Factors Influencing Permanent Deformation of BSMs. Permanent deformation is the accumulation of shear deformation caused by repeated traffic loading. As BSMs fail in permanent deformation, a design function for this material should take the factors influencing permanent deformation into account. The factors influencing permanent deformation of BSMs include

(1) Grading of the parent material

(2) Physical properties of the aggregate particles

(3) Density achieved during compaction

(4) Moisture content (including equilibrium) and moisture susceptibility

(5) Number of load repetitions applied to the material

(6) Magnitude of the applied loads

(7) Stress history of the material

(8) Lateral or confining pressure

(9) The amount of active filler added to the mix

Of these variables, four significant factors were identified for incorporation into a mechanistic design function. The four selected factors are: retained cohesion, percentage of maximum dry density, deviator stress ratio, and permanent strain limit. This was reduced to three factors when the permanent strain limit was included in a reliability function. These factors incorporate an influence of the minor factors to some degree, for example, the grading of the parent material influences the achievable dry density, and the deviator stress ratio includes the effect of moisture in the BSM.

\section{Mix Design of BSM}

3.1. Review of Mix Design. The revision of the BSM mix design was encouraged by the evolution of key performance parameters and appurtenant test methods. Key considerations in this review included

Material variability: selection of appropriate conditioning methods and reliable test methods

Specifications: appropriate guideline limits to provide reliable performance

Duration: streamlining of procedures to minimise the mix design time period

Resource economy: minimisation of new testing equipment and procedures to the essentials

Performance related: evaluate material properties with a reliable link to performance

To achieve the objective of meeting the road industry's needs, each set of issues needed to be considered and addressed. Fortunately, a database with an excess of $300 \mathrm{mix}$ designs using the latest evaluation approach provided the necessary platform for optimising the mix design procedure. 
3.2. Optimisation of Mix Design. A two-part process is required to optimise a BSM mix. Each step requires testing of numerous specimens to take account of the mix composition variables and moisture conditioning of the specimens. To keep the sample size of the aggregate within manageable proportions, ITS tests are selected. Each specimen is $152 \mathrm{~mm}$ diameter and $95 \mathrm{~mm}$ high. The increase from the $100 \mathrm{~mm}$ diameter specimens in the previous decade is to reduce the coefficient of variation of the tests, dictated by the ratio of aggregate size to specimen diameter.

Firstly, the selection of active filler must be undertaken. This is achieved by using three variables of active filler: $1 \%$ lime, $1 \%$ cement or no active filler, and two variables for moisture conditioning: dry or wet. A standard bitumen content is added to each specimen. Three repeat tests are conducted for each set of variables.

Secondly, the selection of optimum bitumen content is undertaken. This includes the selected active filler, four variables of bitumen content, and two variables for moisture conditioning. The trend in ITS results, including the three repeat tests, is plotted as an example in Figure 1.

Taking account of material variability of the repeat tests, the ITS limits from Table 1 can be used to select the design binder content on Figure 2.

The flowchart for BSM mix design is captured in a sequence provided in Figure 2. After ITS testing, there is one final step, i.e., triaxial testing. The challenge was to develop reliable but relatively simple and cost-effective equipment for triaxial testing. This included

Vibratory hammer compaction method: simulates field compaction in producing BSM specimens in the laboratory. Both ITS and triaxial specimens are produced this way.

Triaxial cell: comprises an inflatable tube in a confining cylinder for testing $150 \mathrm{~mm}$ diameter $\times 300 \mathrm{~mm}$ high specimens. It enables a standardised testing procedure. The shear parameters that are determined serve as a BSM classification tool in accordance with Table 2, as well as input into performance models for structural design.

For the first time, the shear strength properties of BSM take cognisance of the RA content for the classification. Research shows that the addition of high RA content generally results in an increase in the cohesion and a slight reduction in the friction angle. At the same time, a higher RA content invariably leads to improved moisture resistance for the BSM. This is captured in an increased retained cohesion value measure for triaxial specimens that have been conditioned under water before testing.

The new compaction methods and test protocols are currently being tailored into SANS norms, although in the interim, they will be included in the revised TG2.

\section{Development of a BSM Transfer Function}

4.1. Architecture of Transfer Function. The failure mechanism for BSMs, permanent deformation (or rutting), is similar to that of granular materials. Therefore, the transfer function for BSMs is based on the design function for

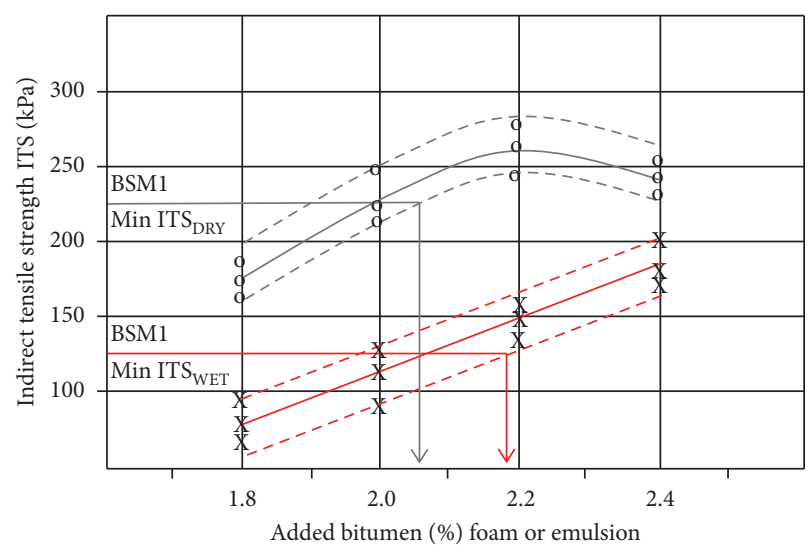

FIGURE 1: Selection of bitumen content from ITS $_{\text {DRY }}$ and ITS $S_{\text {WET }}$.

TABLE 1: Indirect tensile strength limits for classification.

\begin{tabular}{lcc}
\hline Class & \multicolumn{3}{c}{ ITS limits } \\
& $\operatorname{ITS}_{\text {DRY }}(\mathrm{kPa})$ & $\operatorname{ITS}_{\text {WET }}(\mathrm{kPa})$ \\
\hline BSM1 & $>225$ & $>125$ \\
BSM2 & $>175$ & $>100$ \\
\hline
\end{tabular}

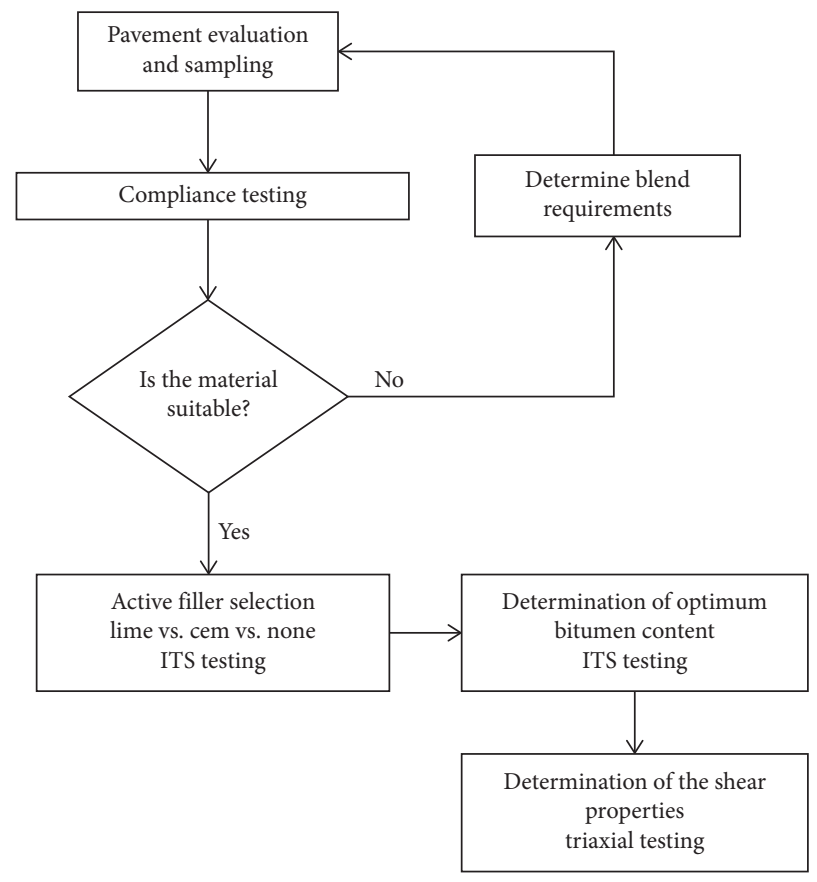

Figure 2: Flowchart for BSM mix design steps.

waterbound macadam shown in equation (1) [10]. The waterbound macadam transfer function calculates the bearing capacity in terms of the number of standard axle load repetitions $(N)$ that can be sustained before a certain level of plastic strain is induced in the layer:

$$
\begin{aligned}
\log N= & 1.891+0.075(\mathrm{RD})-0.009(S)+0.028(\mathrm{PS}) \\
& -1.643(\mathrm{SR}),
\end{aligned}
$$

where $N=$ number of standard axles the layer can sustain before reaching the deformation limit, $\mathrm{RD}=$ relative density 
TABLE 2: Shear parameter limits for triaxial tests.

\begin{tabular}{lcccc}
\hline \multirow{2}{*}{ Class } & RA $(\%)$ & & \multicolumn{2}{c}{ Triaxial } \\
& & Cohesion $(\mathrm{kPa})$ & Friction angle $\left({ }^{\circ}\right)$ & 75 \\
\hline \multirow{2}{*}{ BSM 1 } & $<50$ & 250 & 40 & 38 \\
\hline \multirow{2}{*}{ BSM 2 } & $50-100$ & 265 & 38 & 65 \\
& $<50$ & 200 & 35 & 75 \\
\hline
\end{tabular}

$(\%), S=$ saturation $(\%), P S=$ plastic strain limit as a percentage of the layer thickness (\%), and $\mathrm{SR}=$ stress ratio $(-)$

The resistance to permanent deformation of unbound granular materials under repeated loading can be improved by increasing the density of the material [11]. The durability and performance of a BSM mix depends on its level of compaction [12]. Moisture damage contributes significantly to the deterioration of pavement materials, including BSMs. A reduction in shear strength through moisture ingress, i.e., a higher degree of saturation $(S)$, results in an accelerated rate of permanent deformation [13].

Finally, the rate of permanent deformation accelerates with an increase in deviator stress and decreasing confining pressure [14]. The stress ratio (SR) used in this equation is a function of the load intensity, the shear properties of the materials, as well as the overall pavement structure.

4.2. Stellenbosch BSM Transfer Function. Using the architecture of design function for granular type behaviour, a BSM function can be developed. The new transfer function is based on 14 different roads and 22 different analysis sections as follows:

$$
\log N=A-B(\mathrm{DSR})^{3}+C\left(P_{\mathrm{mod}} \cdot \operatorname{Ret} C\right)+D,
$$

where $\mathrm{DSR}=$ deviator stress ratio as a fraction $(-)$, $P_{\text {mod }}=$ maximum dry density as a percentage of modified AASHTO density (\%), Ret $C=$ retained cohesion (\%), $A=$ constant based on design reliability, and $B, C$, and $D=$ constants from data correlation (Table 3 ).

The DSR term describing the effect of deviator stress on pavement performance yielded a power three function, underlining the importance and sensitivity of this term. The DSR is evaluated at a depth of $25 \%$ of the BSM layer thickness:

$$
\begin{aligned}
\operatorname{DSR} & =\frac{\sigma_{1}-\sigma_{3}}{\sigma_{1, f}-\sigma_{3}}=\frac{\sigma_{1}-\sigma_{3}}{\sigma_{1, f}-\sigma_{3}}, \\
\sigma_{1, f} & =\frac{(1+\sin \phi) \cdot \sigma_{3}+2 \cdot C \cdot \cos \phi}{(1-\sin \phi)},
\end{aligned}
$$

where DSR = deviator stress ratio as a fraction, $\sigma_{1}=$ major principal stress $(\mathrm{kPa}), \sigma_{3}=$ minor principal stress, i.e., confining pressure $(\mathrm{kPa}), \sigma_{1, f}=$ major principal stress at failure $(\mathrm{kPa}), \mathrm{C}=$ cohesion of the BSM default value $(\mathrm{kPa})$, $F=$ friction angle of the BSM default value $\left({ }^{\circ}\right)$, and $F=$ friction angle of the BSM default value $\left({ }^{\circ}\right)$.

4.3. Calibration of BSM Design Function. The purpose of this calibration is to determine values for the constants in
TABLE 3: Reliability coefficient and limits.

\begin{tabular}{lcc}
\hline Reliability (\%) & $A$ & Rut limit $(\mathrm{mm})$ \\
\hline 95 & 0.8436 & 10 \\
90 & 0.9312 & 15 \\
80 & 1.0198 & 20 \\
50 & 1.1369 & 25 \\
\hline
\end{tabular}

equation (2) and to best describe the relative influence of each of the input variables on BSMs. The transfer function relates the number of standard axles the pavement can accommodate with the remaining amount of permanent strain in the BSM layer, i.e., a limiting value set in by design criteria. This enables the designer to specify the amount of permanent deformation that may occur before the BSM is deemed to have failed, linked to the design reliability.

Figure 3 shows the comparison of the accumulation of plastic strain due to repeated loading ( $N$ actual) compared to the prediction of remaining life, using the new transfer function $(\mathrm{N}$ $\mathrm{TF})$. The calibration process aims to reduce the difference between the estimated life and the actual life of BSMs.

4.4. Long-Term Pavement Performance Data. The transfer function can be calibrated to perfectly describe a specific case if the information is sufficient. However, this will not be useful as it will only describe the life of a specific BSM on a local scale, limiting the relevance for design. By investigating a number of pavement structures, with data available at multiple points in time, the transfer function can be calibrated to describe the life of BSMs on a more extensive scale.

Data such as the material properties and subsequent long-term performance of pavement structures were gathered and analysed in the permanent deformation model. For an overall representation of the properties and performance of BSMs, results of fourteen long-term pavement performance (LTPP) studies were interrogated. This was part of a long-term pavement performance study, by SANRAL. Each of these pavements either had a BSM 1 or BSM 2 base layer with a minimum thickness of $100 \mathrm{~mm}$. In total, 69 LTPP sections have played a role in data provisions and shaping the design functions.

The data available for these pavements included densities, moisture contents, layer thicknesses, material types, and classes as well as traffic data. The data also included FWD and rut depth measurements at different stages in their field life. The information used during the analysis of these pavements is discussed in detail by Long and Jooste [15]. A summary of the information available for these pavements is presented in Table 4. 


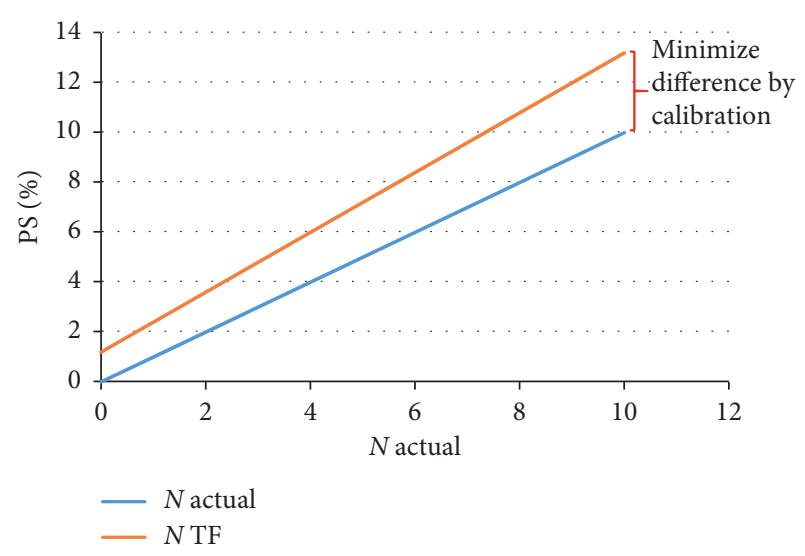

FIgURE 3: Transfer function prediction compared to actual load repetitions [10].

TABLE 4: LTTP pavement information [10].

\begin{tabular}{lccc}
\hline Road & $\begin{array}{c}\text { BSM construction } \\
\text { year }\end{array}$ & $\begin{array}{c}\text { BSM thickness } \\
(\mathrm{mm})\end{array}$ & $\begin{array}{c}\text { Standard axles } \\
\text { accommodated } \\
\text { to date (MESA) }\end{array}$ \\
\hline MR27 & 1988 & 100 & 5 \\
MR504 & 1995 & 175 & 1.6 \\
(A) & & 175 & 1.6 \\
MR504 & 1995 & 100 & 17 \\
(B) & 1984 & 150 & 14 \\
N1-1 & 1980 & 150 & 14 \\
N1-13 & 1980 & 140 & 3.4 \\
N1-14 & 1980 & 180 & 2.4 \\
N2-16 & 2000 & 170 & 5.6 \\
N2-20 & 1997 & 150 & 6.7 \\
N4-1 & 1996 & 280 & 1.1 \\
N4-5X & 2004 & 100 & 18 \\
N11-8 & 1974 & & \\
N12- & & 135 & 18 \\
19(3) & 1974 & 250 & 0.48 \\
N12- & 2000 & & \\
19(4) & & & \\
P243-1 & & & \\
\hline
\end{tabular}

Areas of insufficient data required assumptions to be made based on the performance and conditions of these pavements. Where cohesion $(C)$, friction angle $(\phi)$, and retained cohesion values were not available, realistic and representative default values were used. Reasonable and conservative values were applied for each pavement, based on the minimum design values specified in the TG2 [9].

The data obtained from these pavements were used for the calibration of the transfer function. The structures of each of these pavements was modelled in Rubicon Toolbox to determine the critical (highest) DSR value when subjected to an $80 \mathrm{kN}$ standard axle load (E80). The software required the layer thicknesses and material properties for each of the LTPP pavements to calculate the DSR.

4.5. Permanent Strain Development with Repeated Loading. The new BSM transfer function uses permanent strain as the limiting factor when determining the life of a BSM. During the analysis of the pavements used to calibrate the transfer function, rutting measurements were taken at different points in time. The rutting measurements reflect the permanent deformation of the pavement structure as a whole. A percentage of the total permanent deformation was used to obtain the permanent deformation within the BSM base layers.

The accumulated permanent strain in the BSM layers of the LTPP pavements varies for each pavement. This poses a challenge for the calibration of the transfer function. Pavements that showed little deformation would reflect early life permanent deformation behaviour, while pavements that showed more significant deformation would reflect the long-term permanent deformation behaviour. This only allows the rate of permanent deformation accumulation for different pavements to be compared and not the absolute values.

In order to obtain values for the actual traffic at higher strain levels, the Huurman model for permanent strain development was implemented for each pavement. The Huurman model for PS development was used to determine the number of load repetitions at each of these PS levels up to the final level of $10 \%$. The Huurman model for PS prediction is as follows [16]:

$$
\varepsilon_{p}=A \cdot\left(\frac{N}{1000}\right)^{B}
$$

where $N=$ number of load repetitions, $\varepsilon_{p}=$ plastic strain accumulation (\%), and $A$ and $B=$ regression constants.

4.6. Calibration of the New BSM Transfer Function. The data obtained from the fourteen LTPP pavements were used for the calibration of the transfer function. The transfer function's prediction of the number of load repetitions $(\mathrm{N} \mathrm{TF})$ to reach a specific level of permanent strain was compared to the estimated traffic ( $\mathrm{N}$ estimate) that the various pavements accommodated to reach that strain level.

Figure 4 illustrates a comparison of the transfer function's predictions compared to the estimated traffic over a range of permanent strain values. An estimation was considered good if it predicted a value close to the estimated value. By using a large number of data points, the slope of linear trendline through the data was used to determine the function's accuracy. A slope greater than one indicates that the function overestimates the life of the layer, whereas a slope smaller than one would indicate underestimation.

The transfer function was calibrated using linear regression to determine the values of $A, B, C$, and $D$ that yielded a slope of one, while minimizing the dispersion of data points. The comparison between the calibrated transfer function and the estimated traffic is shown in Figure 5. The calibrated transfer function is shown in equation (5). In this figure, the slope of the trendline (the dotted line) correlates very well with the one-to-one relationship.

The trendline for the calibrated transfer function was $y=1.0006 x+1.0572$. The slope of the trendline was deemed to be a good representation of the estimated life. However, the intersect point (1.0572) indicates that the transfer 


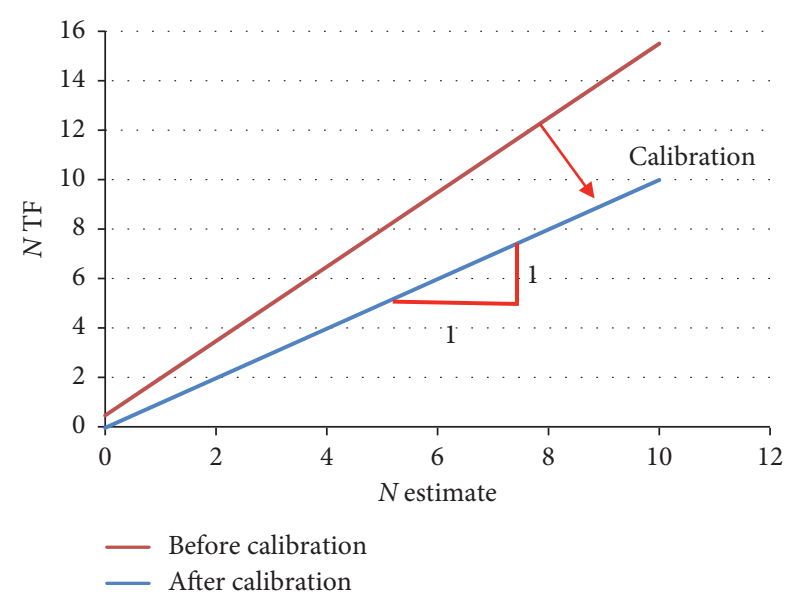

Figure 4: Measure of transfer function's accuracy [10].

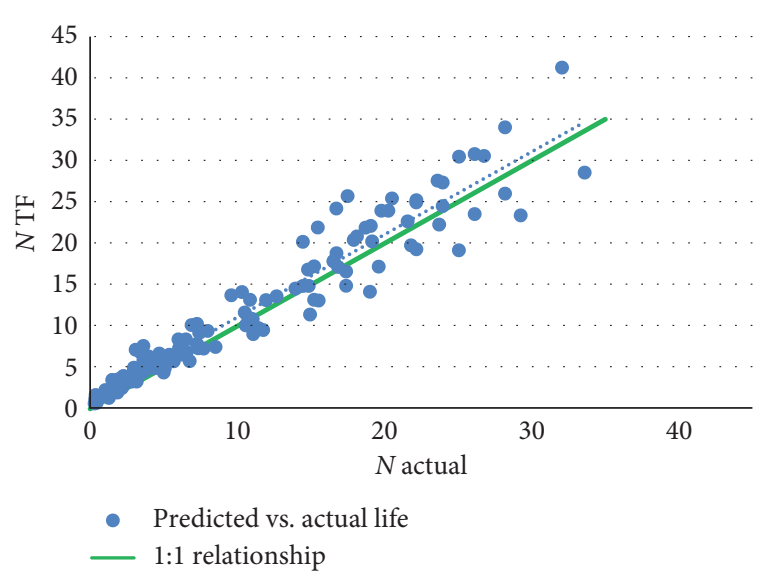

FIGURE 5: Predictions of the calibrated transfer function compared to actual traffic [10].

function may overestimate the life of the material at low remaining strain values. This is due to the logarithmic nature of the function, which produces positive results even when the remaining strain is very small (or zero). Therefore, it is recommended that a limit to the minimum remaining strain is set in place for design purposes.

Permanent strain development obtained from traffic estimation was compared to that of the transfer function for each of the LTTP pavement structures. Figure 6 shows this relationship between predicted and actual life for a section of the MR502. It highlights significant differences in correlation at low strain levels. The slope of transfer function's predicted vs. actual life at higher strain levels is close to parity. This indicates that the transfer function accurately predicts the long-term permanent strain development of the BSM.

4.7. Safety Adjustments for Design. The new transfer function for BSMs is calibrated to best describe the observations made from the LTPP data. This function only aimed to describe the observed trends. A design function, however, requires different levels of reliability to be explicitly built into the

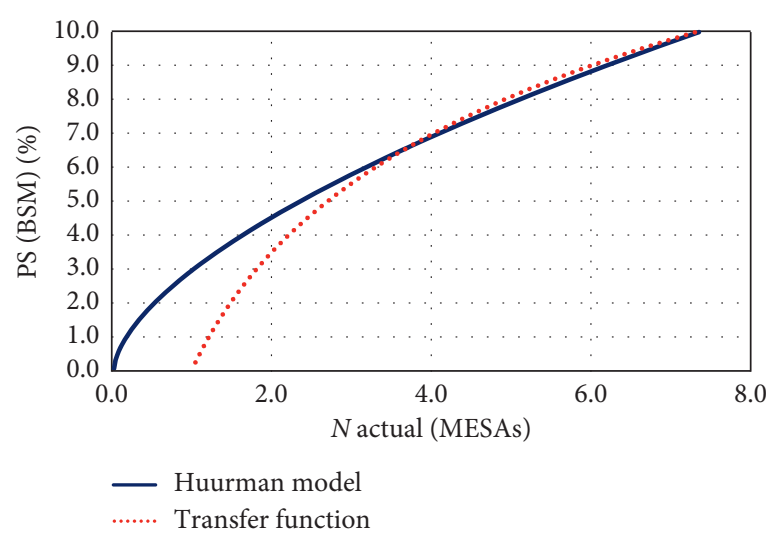

FiguRE 6: Transfer function's permanent strain prediction for MR504 (A) [10].

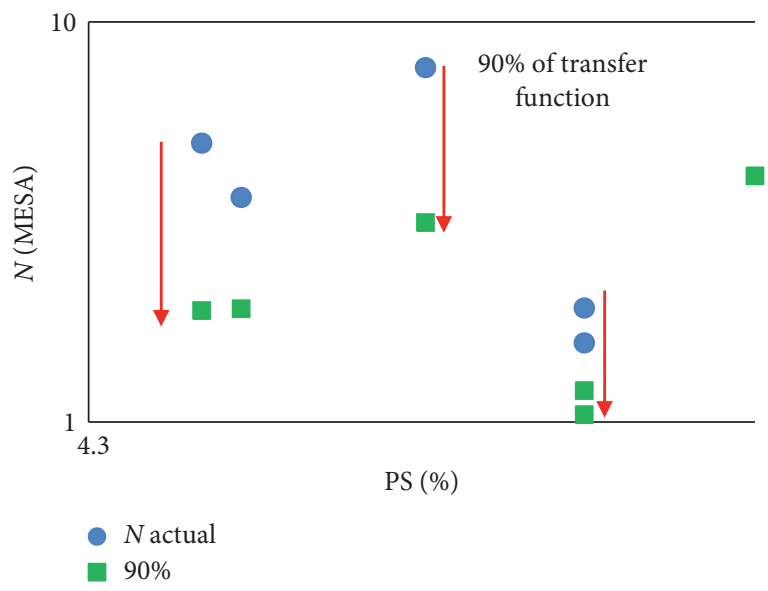

FIGURE 7: Reducing the transfer function's predictions to increase reliability [10].

function. Based on South African pavement design, four categories and appurtenant reliability have been incorporated into the transfer function, i.e., category A (95\% reliability), category B (90\% reliability), category C (80\% reliability), and category $D(50 \%)$.

The calibration process was repeated by only adjusting the value of constant $A$, which adjusts the prediction of functions without altering the relationship between the function's variables. Reliability in the transfer function was measured as the percentage of data predicted by the transfer function that had a smaller value than the observed data. Figure 7 illustrates the principles used to calibrate the transfer function to different levels of reliability. It is shown that the transfer function produced lower life predictions than was estimated for $90 \%$ of the data points.

The new design function's prediction of the LTPP life compared to the estimated life is shown in Figure 8. The slope of the transfer functions predictions compared to the estimated life reduces with the increase in reliability. The reduction in slope indicates that the transfer function underestimates the life of the material by higher margins. This underestimation increases the probability of a designed material to achieve the calculated design life. 


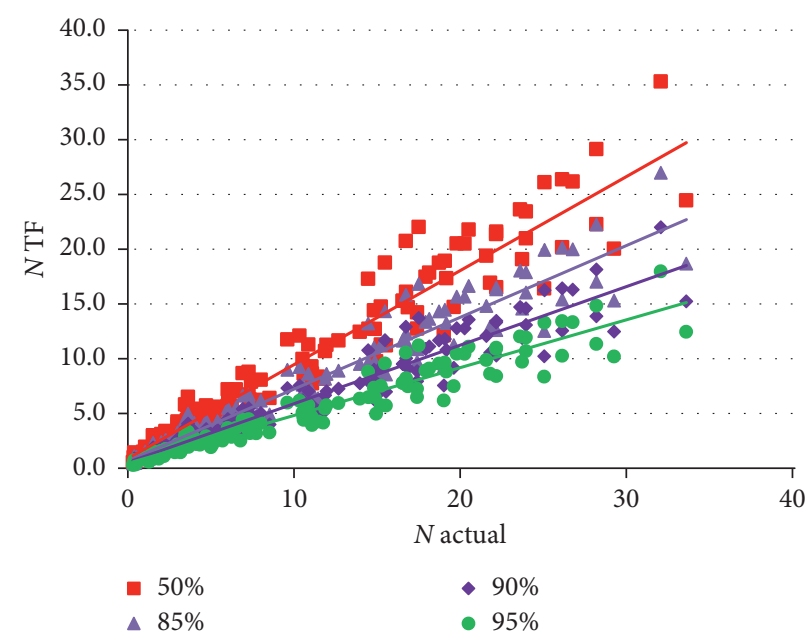

FIgURE 8: Underestimation of life at different levels of reliability [10].

Table 5: Pavement structures for design comparison [10].

\begin{tabular}{|c|c|c|c|c|c|c|}
\hline Pavement & Pavement layer & Material class & Thickness $(\mathrm{mm})$ & Stiffness (MPa) & \multicolumn{2}{|c|}{ BSM properties } \\
\hline \multirow{5}{*}{1} & Surfacing & HMA & 35 & 3500 & $C(\mathrm{kPa})$ & 250 \\
\hline & Base & BSM 1 & 250 & 720 & $\varphi\left({ }^{\circ}\right)$ & 40 \\
\hline & Sub-base & G5 & 250 & 240 & $\operatorname{RetC}(\%)$ & 75 \\
\hline & Selected subgrade & G8 & 180 & 120 & $P_{\text {mod }}(\%)$ & 100 \\
\hline & Subgrade & G8 & N/A & 90 & & \\
\hline \multirow{5}{*}{2} & Surfacing & HMA & 20 & 2500 & $\mathrm{C}(\mathrm{kPa})$ & 225 \\
\hline & Base & BSM 2 & 280 & 500 & $\varphi\left({ }^{\circ}\right)$ & 39 \\
\hline & Sub-base & G6 & 250 & 200 & $\operatorname{Ret} C(\%)$ & 70 \\
\hline & Selected subgrade & G8 & 150 & 100 & $P_{\text {mod }}(\%)$ & 98 \\
\hline & Subgrade & G8 & $\mathrm{N} / \mathrm{A}$ & 90 & & \\
\hline
\end{tabular}

The new calibrated BSM design function is shown in equation (5). The design function can be used to estimate the life of BSMs for design purposes. However, this function's use should be compliant with rules outlined in TG2 [17] where allocated materials stiffness and analysis positions in the BSM layer are outlined.

$$
\begin{aligned}
\log N= & A-57.286(\mathrm{DSR})^{3}+0.0009159\left(P_{\bmod } \cdot \operatorname{Ret} C\right) \\
& +0.86753
\end{aligned}
$$

\section{Design Method Comparison}

As part of the validation process, the new function was compared to the older design methods for BSMs. In Bierman's research [10], five different pavement structures were initially investigated, and the results were compared. These analyses were carried out before a structural pavement design procedure was developed. The methods included a heuristic design pavement number (PN) method and the mechanistic-empirical (ME) method. Unfortunately, the analysis was carried out before the PN method, which required updating with new data and recalibration. Nevertheless, reasonable pavement life comparisons were developed.
The Stellenbosch BSM design function, however, could be applied using the updated TG2 [17], thus providing more realistic insights. These results are presented in this paper. Focus was placed on a comparison with the old and new PN design methods [7, 18], and the lives of ten different pavement structures were compared. Only two of these structures are highlighted in this paper (see Table 5).

There are fundamental differences between the heuristic $\mathrm{PN}$ design method and the ME method. The PN provides an estimate of pavement life of the entire pavement structure based on performance of the LTPP pavements with BSM layers. The architects of the PN methods used ME analysis to develop the design model, so a design only needs to input the pavement materials' classifications and structure. The Stellenbosch BSM design function interrogates the structural mechanics of each layer to determine the "weakest link" and thus determine the design life.

The comparison between the design life of the selected pavements using the different design models is provided in Figures 9(a) and 9(b). The variables included in the life calculation include

Design models: PN method old-2009 and new-2019 as well as Stellenbosch BSM ME Design function

Reliability levels: 95\% (category A) and 90\% (category B). 

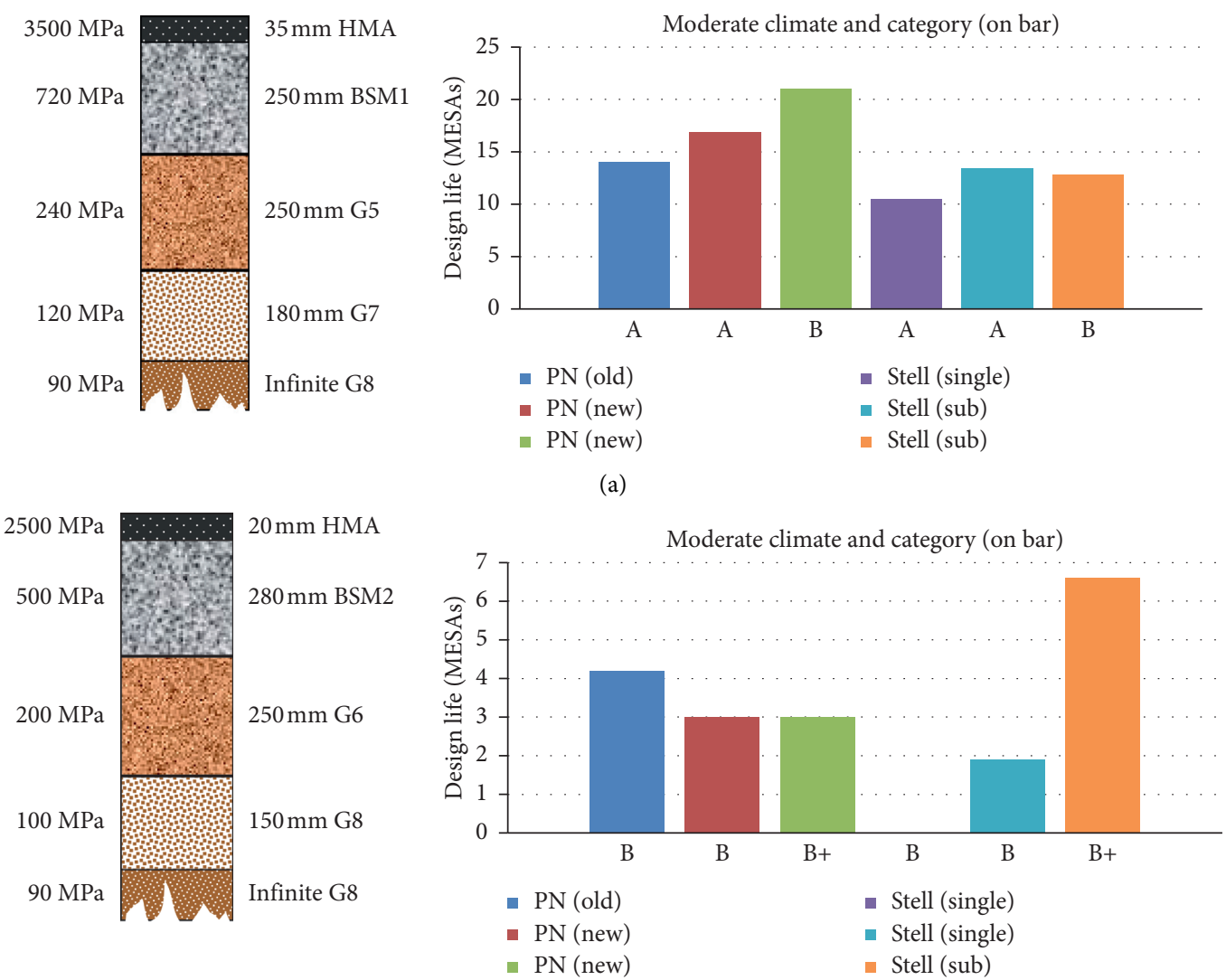

(b)

Figure 9: (a) Design life of pavement 1 with BSM1 base vs. design method. (b) Design life of pavement 2 with BSM2 base vs. design method.

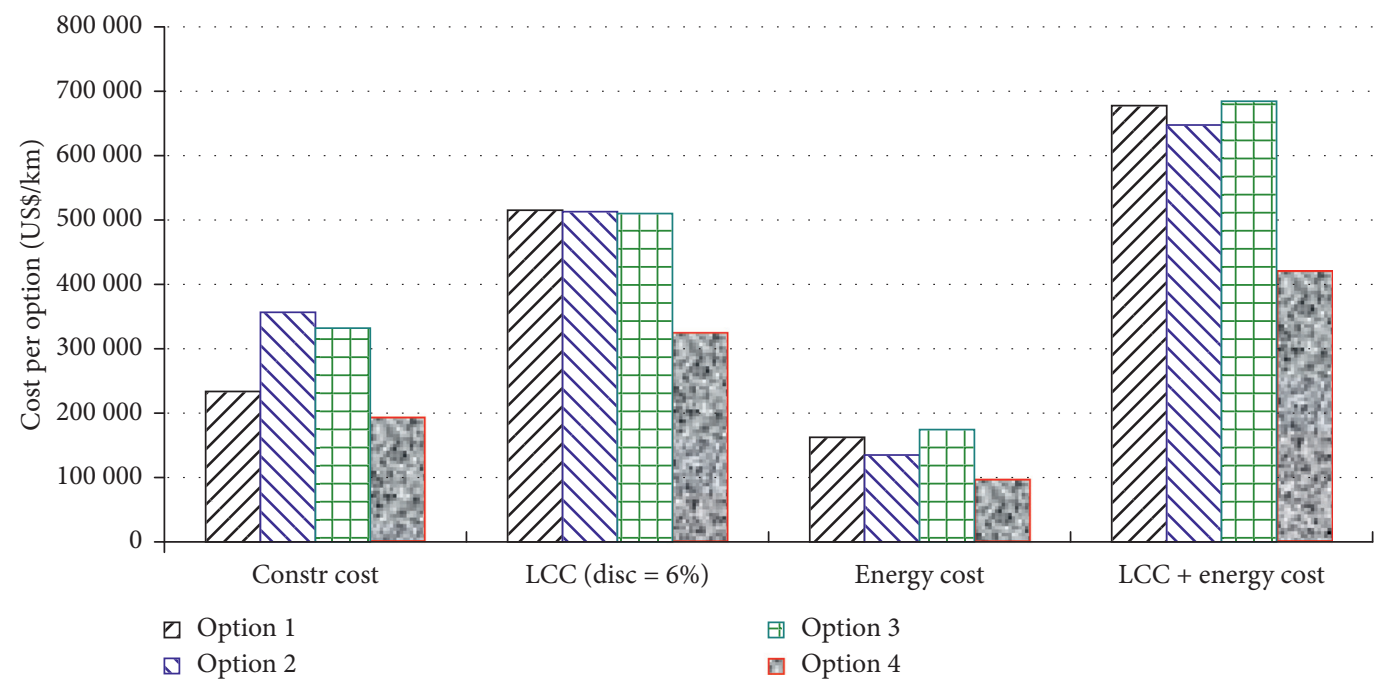

Figure 10: Combined life cycle cost and energy consumption [19].

Layer ME analysis of BSM: single layer vs. sublayer (at least $100 \mathrm{~mm}$ )

BSM Classification: BSM1 vs. BSM2

Default values for BSM properties based on the TG2 [17] guidelines
The pavement life determined using the $\mathrm{PN}$ method compares well with the new Stellenbosch ME BSM design function. Sensitivity to design reliability is evident. Sublayering of the BSM layer and using an analysis position at $1 / 4$ depth of the layer provide a more realistic design life. It should be noted that sublayering provides a more 
representative density profile and resilient modulus profile for a thick layer of material that is stress-dependent.

\section{Economics}

Jenkins and Collings [19] compared four different rehabilitation strategies in terms of life-cycle costing and energy consumption, based on actual projects. The four interventions were

(1) Patch and overlay

(2) Mill and replace

(3) Cement stabilise the existing base + surfacing and overlay

(4) Recycle using bitumen stabilisation technology.

It is obvious in Figure 10 that initial construction costs alone are inadequate for selection of rehabilitation alternatives. They can provide skewed and unrealistic rehabilitation selection, which will lead to unnecessary wastage of resources. Cheapest is the dearest.

The whole-of-life analysis using PWOC (present worth of costs) provides more realistic financing requirements for pavement upkeep over the entire analysis period. The combined energy and life cycle costs provide the most informative insight into sustainable solutions. For this particular project, bitumen stabilisation technology scores as the most cost-effective and sustainable solution for rehabilitation.

In this case, energy is used as a surrogate for emissions too; however, life cycle analysis (LCA) approach would be the ultimate way to analyse different rehabilitation interventions.

\section{Conclusions}

The past decade has provided the opportunity to gather invaluable performance data of BSMs from several hundred mix designs and 69 LTPP sections. In turn, these data have provided the opportunity to upgrade the design and application and bitumen stabilised materials (BSMs). Some of the highlights of areas where BSMs are being taken forward by many strategic developments include

Guidelines for a refined mix design method for BSMs including:

$$
\begin{aligned}
& \text { Vibratory hammer compaction of ITS and triaxial } \\
& \text { specimens } \\
& \text { Phased analysis to determine active filler (type and } \\
& \text { content) and binder content for optimal performance } \\
& \text { Triaxial testing of the proposed mix to evaluate shear } \\
& \text { properties at equilibrium and wet conditioning to be } \\
& \text { used in material classification and provide inputs into } \\
& \text { structural design } \\
& \text { Certification of all test procedures using SANS } \\
& \text { standards }
\end{aligned}
$$

An updated material classification system that uses significantly more materials data to provide a more robust method for evaluation and design
An upgrade pavement number design system that removed biases and provides for a greater range of types of pavement structures and more accurate design outcomes based on extended data

A new mechanistic-empirical design system for BSMs based on extensive analysis of LTPP sections and performance parameters of the BSM

Economic and environmental (energy consumption) analyses provide important insight into the sustainability of rehabilitation options and highlights the advantages of cold recycling technology

The improved understanding of key performance parameters of BSMs and implementation of these findings in the application of the technology will offer more effective and reliable solutions in pavement rehabilitation.

\section{Data Availability}

The research data that have been used in this publication emanates from research at Stellenbosch University and is clearly referenced. Additional data can be obtained from the accredited publications in the reference list.

\section{Conflicts of Interest}

The authors declare that they have no conflicts of interest.

\section{Acknowledgments}

The authors acknowledge the financial support provided by Roadmac Surfacing Cape to Mr Carl Bierman in carrying out this research project.

\section{References}

[1] L. H. Csanyi, Foamed Asphalt in Bituminous Paving Mixes, Highway Research Board Bulletin, Washington, DC, USA, 1957.

[2] S. M. Acott and P. A. Myburgh, "Design and performance study of sand bases treated with foamed asphalt," Transportation Research Record, vol. 898, pp. 290-296, 1982.

[3] F. M. L. Akeroyd and B. J. Hicks, Foamed Bitumen Road Recycling, Alad Limited, London, UK, 1988.

[4] F. M. L. Akeroyd, "Advances in foamed bitumen technology," in Proceedings of the 5th Conference on Asphalt Pavements for Southern Africa, Mbabane, Swaziland, June 1989.

[5] SABITA, GEMS-The Design and Use of Granular Emulsion Mixes, Southern African Bitumen Association, Cape Town, South Africa, 1993.

[6] SABITA, ETB-The Design and Use of Emulsion Treated Bases, Southern African Bitumen Association, Cape Town, South Africa, 1999.

[7] SABITA, The Design and Use of Foamed Bitumen Treated Materials, Southern African Bitumen Association, Cape Town, South Africa, 2002.

[8] D. Collings and K. Jenkins, "The long-term behaviour of bitumen stabilised materials," in Proceedings of the 10th Conference on Asphalt Pavements for Southern Africa, Drakensberg, South Africa, 2011.

[9] Asphalt Academy, Technical Guideline TG2: Bitumen Stabilised Materials: A Guideline for the Design and Use of Bitumen 
Emulsion and Foamed Bitumen Stabilised Materials, Asphalt Academy, Cape Town,South Africa, 2009.

[10] C. R. Bierman, A Design Function for Bitumen Stabilised Material Performance Based on Laboratory and Field Evaluation: MEng (Research), Stellenbosch University, Stellenbosch, South Africa, 2017.

[11] A. A. Van Niekerk, "Mechanical behavior and performance of granular bases and sub-bases in pavements," Doctoral degree, Technical University Delft, Delft, Netherlands, 2002.

[12] K. J. Jenkins, "Mix design considerations for cold and halfwarm bituminous mixes with emphasis on foamed bitumen," Doctoral degree, University of Stellenbosch, Stellenbosch, South Africa, 2000.

[13] F. Lekarp, U. Isacsson, and A. Dawson, "State of the art II : permanent strain response of unbound aggregates," Journal of Transportation Engineering, vol. 126, no. 1, 2000.

[14] S. Werkmeister, Permanent Deformation Behaviour of Unbound Granular Materials in Pavement Constructions, Technischen Universitat Dresden, Dresden, Germany, 2003.

[15] F. Long and F. Jooste, Summary of LTTP Emulsion and Foamed Bitumen Treated Sections, Technical Memorandum, Sabita, Cape Town, South Africa, 2007.

[16] M. Huurman, "Permanent deformation in concrete block pavements," Doctoral degree, Technical University Delft, Delft, Netherlands, 1997.

[17] Asphalt Academy, Technical Guideline TG2: Bitumen Stabilised Materials: A Guideline for the Design and Construction of Bitumen Emulsion and Foamed Bitumen Stabilised Materials, Asphalt Academy, Pretoria, South Africa, 3rd edition, 2020.

[18] Asphalt Academy, Technical Guideline TG2: Bitumen Stabilised Materials: A Guideline for the Design and Construction of Bitumen Emulsion and Foamed Bitumen Stabilised Materials, Asphalt Academy, Pretoria, South Africa, 2nd edition, 2009.

[19] K. J. Jenkins and D. C. Collings, "Combining LCC and energy consumption for enhancing decision making regarding rehabilitation options," in Proceedings of the 10th Conference on Asphalt Pavements for Southern Africa, Drakensberg, South Africa, 2011. 